\title{
Visual Pathway for the Optokinetic Reflex in Infant Macaque Monkeys
}

\author{
Claudia Distler and Klaus-Peter Hoffmann \\ Department of General Zoology and Neurobiology, Faculty of Biology and Biotechnology, Ruhr-University Bochum, D-44780 Bochum, Germany
}

The horizontal optokinetic nystagmus (hOKN) in primates is immature at birth. To elucidate the early functional state of the visual pathway for hOKN, retinal slip neurons were recorded in the nucleus of the optic tract and dorsal terminal nucleus (NOT-DTN) of 4 anesthetized infant macaques. These neurons were direction selective for ipsiversive stimulus movement shortly after birth [postnatal day 9 (P9)], although at a lower direction selectivity index (DSI). The DSI in the older infants (P12, P14, P60) was not different from adults. A total of $96 \%$ of NOT-DTN neurons in P9, P12, and P14 were binocular, however, significantly more often dominated by the contralateral eye than in adults. Already in the youngest animals, NOT-DTN neurons were well tuned to different stimulus velocities; however, tuning was truncated toward lower stimulus velocities when compared with adults.

As early as at P12, electrical stimulation in V1 elicited orthodromic responses in the NOT-DTN. However, the incidence of activated neurons was much lower in infants ( $40-60 \%$ of the tested NOT-DTN neurons) than in adults (97\%). Orthodromic latencies from V1 were significantly longer in P12-P14 $(x=12.2 \pm 8.9 \mathrm{~ms})$ than in adults $(x=3.51 \pm 0.81 \mathrm{~ms})$. At the same age, electrical stimulation in motion-sensitive area MT was more efficient in activating NOT-DTN neurons ( $80 \%$ of the tested cells) and yielded shorter latencies than in $\mathrm{V} 1(x=7.8 \pm 3.02 \mathrm{~ms}$; adult $x=2.99 \pm 0.85 \mathrm{~ms})$.

The differences in discharge rate between neurons in the NOT-DTN contra- and ipsilateral to the stimulated eye are equivalent to the gain asymmetry between monocularly elicited $0 \mathrm{KN}$ in temporonasal and nasotemporal direction at the various ages.

\section{Introduction}

The visual system of primates is immature at birth. Biologically relevant movement and objects, i.e., putative food and predators, or in humans, the mother's face are recognized innately shortly after birth, other stimuli can only be processed and learned weeks or months after birth. Supposedly the early "innate" visual processing is accomplished by subcortical structures, whereas "learned" visual processing depends on visual cortex (Sewards and Sewards, 2002). Visual functions and their underlying cortical machinery improve postnatally at different rates. In human and macaque infants perception of simple motion is present early after birth (Kiorpes and Movshon, 2004). Perception of coherent motion and pattern motion develops later, i.e., $\sim 7$ weeks of age and matures through the first year of life in humans (Braddick et al., 2003; Mason et al., 2003), and between 10 and 18 weeks in macaques (Hall-Haro and Kiorpes, 2008).

The horizontal optokinetic reflex (hOKR) is a basic mechanism to stabilize the image of the visual environment on the

\footnotetext{
Received Aug. 22, 2011; revised 0ct. 6, 2011; accepted 0ct. 23, 2011.

Author contributions: C.D. and K.-P.H. designed research; C.D. and K.-P.H. performed research; C.D. and K.-P.H. analyzed data; C.D. and K.-P.H. wrote the paper.

This work was supported by Grant SFB 509/B2 from the Deutsche Forschungsgemeinschaft and by a ZEN grant from the Hertie Foundation to K.-P.H. We thank H. Korbmacher and S. Dobers for expert technical assistance and W. Junke for software development.

Correspondence should be addressed to Klaus-Peter Hoffmann at the above address. E-mail: kph@ neurobiologie.rub.de.

DOI:10.1523/JNEUROSCI.4302-11.2011

Copyright $\odot 2011$ the authors $\quad 0270-6474 / 11 / 3117659-10 \$ 15.00 / 0$
}

retina. In mammals, its key visuomotor interface is the nucleus of the optic tract and the dorsal terminal nucleus (NOT-DTN). Their direction selective neurons receive visual information directly from the contralateral eye and, in primates, also from the ipsilateral eye and indirectly via visual cortical areas. Retinal slip cells in NOT-DTN code the velocity error between stimulus displacement and eye movement in a direction-selective ipsiversive manner, i.e., cells in the left NOT-DTN are activated by stimulation to the left and vice versa. They project to the nucleus prepositus hypoglossi, the inferior olive and the dorsolateral pontine nucleus, and via the cerebellum and the deep cerebellar nuclei to the oculomotor nuclei (Simpson et al., 1988; Mustari et al., 1994; Büttner-Ennever et al., 1996).

Developmental studies in cats and primates indicate that hOKR is asymmetrical during monocular viewing (mhOKR) early after birth but reaches symmetry some weeks or months postnatally (Van Hof-Van Duin, 1978; Atkinson, 1979; Malach et al., 1981; Naegele and Held, 1982). In macaques mhOKR can be elicited in temporonasal and, albeit much weaker, also in nasotemporal direction already $3 \mathrm{~d}$ after birth. At lower stimulus velocities, symmetry of mhOKR develops gradually at 2-5 weeks of age, at higher velocities at 12 weeks or later (Distler et al., 1999). No sudden increase of symmetry occurs at a certain age as in cat (Van Hof-Van Duin, 1978), or as expected due to the sudden maturation of the cortical pathway for motion analysis at 3 months of age (Distler et al., 1996). In cats, at 3 weeks of age when mhOKR can only be elicited in temporonasal direction NOT-DTN neurons are exclusively driven by the contralateral eye. By 4 weeks of age, mhOKR becomes bidirectional and many NOT-DTN cells become binocular probably due to 
a maturing binocular cortical input (Distler and Hoffmann, 1993), a prerequisite for symmetrical OKR.

In the present study we correlate the neuronal response properties of NOT-DTN neurons and cortical input in infant macaques between 1 week and 2 months of age with the development of OKR.

\section{Materials and Methods}

Animals. All experiments were approved by the local authorities (Regierungspräsidium Arnsberg) and were performed in accordance with the Deutsche Tierschutzgesetz of April 12, 2001, the European Council Directive of November 24, 1986 (S6 609 EEC), and the National Institutes of Health guidelines for care and use of animals for experimental procedures.

Data were collected from four infant macaques of both sexes, three Macaca mulatta at postnatal day 9 (P9), P12, P60, one M. fascicularis at $\mathrm{P} 14$, and 6 adults. The data from the adults were in part used in earlier publications but reanalyzed for the present study (Hoffmann and Distler, 1989; Hoffmann et al., 1991, 2009). The infant rhesus monkeys were born in our animal facility of the Department of Zoology and Neurobiology, the cynomolgous monkey was purchased from a local breeder (Covance).

Surgery. The animals were initially treated with $0.1 \mathrm{mg} / \mathrm{kg}$ atropine sulfate and anesthetized with $25 \mathrm{mg} / \mathrm{kg}$ ketamine hydrochloride. In the P9 and the P12 animals ketamine was supplemented with $0.8 \mathrm{mg} / \mathrm{kg}$ xylazine (Rompun). After local anesthesia with xylocaine the animals were intubated, and an intravenous catheter was introduced into the saphenous vein. The animals were placed in a stereotactic frame and artificially ventilated throughout the experiment with nitrous oxide/oxygen as $3: 1$ and $0.3-1 \%$ halothane as needed. In the adults we used nitrous oxide/oxygen as $3: 1$ supplemented by pentobarbital $(1 \mathrm{mg} / \mathrm{kg} / \mathrm{h})$. Considering that pentobarbital at dosages rather higher than the one used in our early experiments has a mostly depressing effect on neuronal activity (Olds and Ito, 1973; Hyvärinen et al., 1979; Kaitin, 1985; Chen and Godfrey, 2000; Cechetto et al., 2001; Wang et al., 2010) it seems unlikely that differences in response properties, e.g., concerning stimulus driven activity, direction selectivity, or velocity tuning of infant and adult monkeys (see below) could be attributed to different anesthesia.

Deep analgesia was ensured by a bolus of $3 \mu \mathrm{g} / \mathrm{kg}$ fentanyl followed by an infusion of $3 \mu \mathrm{g} \cdot \mathrm{kg}^{-1} \cdot \mathrm{h}^{-1}$ fentanyl in the infant but not in the adult monkeys. This dosage is habitually used in a variety of species and has been shown not to cause any systematic alterations in response properties in superior colliculus and visual cortex (e.g., cat: Grewing, 2004; ferret: Kalberlah et al., 2009, Distler et al., 2009; monkey: Logothetis et al., 1999; Riecanský et al., 2005).

Body temperature, heart rate, $\mathrm{SPO}_{2}$, and end-tidal $\mathrm{CO}_{2}$ were monitored and maintained at physiological levels. Corneae were protected by contact lenses chosen with a refractometer (Rodenstock) to focus the eye on the screen. After additional local anesthesia with bupivacaine hydrochloride (Bupivacain, Jenapharm) the skin overlying the skull was cut and craniotomies were performed to allow access to primary visual cortex (V1), to the middle temporal area (MT), and to the superior colliculus (SC) and pretectum. After completion of all surgical procedures the animals were paralyzed with alcuronium chloride (Alloferin).

Electrical stimulation. Electrical stimulation consisted of single pulses $100-200 \mu$ s wide at stimulus strengths between $0.07 \mathrm{~mA}$ and $1.0 \mathrm{~mA}$ delivered via pairs of concentric stimulation electrodes (P9, P12, P14) or low impedance tungsten in glass microelectrodes (P14, P60). The spread of electrical current depends on the strength of the current, the resistance of the electrode, and the excitability constant. An estimate of the spread of the effects of electrical stimulation with the currents used can be deduced from an equation given by Asanuma and Sakata (1967) for monopolar intracortical stimulation of pyramidal tract neurons. A cathodal pulse of $0.1 \mathrm{~ms}$ duration and $0.5 \mathrm{~mA}$ current would excite cells as well as axons up to a distance of $0.5 \mathrm{~mm}$. We assume that the layer $\mathrm{V}$ pyramidal cells projecting to the NOT-DTN would behave similarly. A direct measurement in cat visual cortex indicates that effective current spread amounts to $\sim 200 \mu \mathrm{m}$ at currents of $200 \mu \mathrm{A}$ (Ronner et al., 1981;
Table 1. NOT-DTN data summary

\begin{tabular}{llcllllc}
\hline Animal & Number of cells & v-tune & OD & DSI & vis. lat. & V1 tested & MT tested \\
\hline P9 & 19 & 9 & 18 & 18 & 10 & 12 & 0 \\
P12 & 37 & 8 & 29 & 33 & 20 & 32 & 0 \\
P14 & 42 & 14 & 23 & 25 & 20 & 42 & 42 \\
P60 & 36 & 17 & 22 & 24 & 21 & 33 & 33 \\
Adult & 94 & 21 & 39 & 94 & 29 & 32 & 89 \\
\hline
\end{tabular}

Summary of the number of recorded NOT-DTN cells and the number of cells tested for various parameters: velocity tuning (v-tune), OD, DSI, visual latency (vis. lat.), and electrical stimulation in V1 and MT.

Nowak and Bullier, 1996; Tehovnik et al., 2006). Thus, we estimate the current spread in our experiments to amount to maximally $1000 \mu \mathrm{m}$ around the electrode. Two electrodes were placed in the operculum in the parafoveal representation of V1 (P9, P12, P14, P60), and one in area MT $(\mathrm{P} 14, \mathrm{P} 60)$ after recording the characteristic direction selective activity of MT neurons. The correct position of the stimulation and recording sites was verified histologically in Nissl- or Klüver-Barrera-stained sections.

Visual stimulation. In the early experiments (P9, P12) full field visual stimuli consisted of random dot patterns projected onto a tangent screen via a slide projector. The patterns could be moved along linear or circular paths by a galvanometer-driven double-mirror system (Hoffmann and Distler, 1989; Hoffmann et al., 2009). In the later experiments (P14, P60) random dot patterns were created with NEUROSTIM and presented on a $100 \mathrm{~Hz}$ computer screen in front of the animal. The patterns were chosen or adapted according to the neurons' requirements to yield maximal responses. In adults both stimulation methods were applied in the same study on MT-MST neurons without yielding any obviously different results (Hoffmann et al., 2009).

Data analysis. Peristimulus-time histograms were analyzed using homemade programs written in MATLAB (The MathWorks, Inc.).

To judge a cell's direction selectivity, the response strength (spikes/s) during stimulation in the preferred direction (PD) and the non-preferred direction (NPD) was compared, and a direction selectivity index (DSI) was calculated as follows: $\mathrm{DSI}=(\mathrm{PD}-\mathrm{NPD} / \mathrm{PD}) \times 100$. DSIs close to 100 indicate high, indices close to zero indicate low direction selectivity.

The ability of both eyes to drive individual neurons in the NOT-DTN was assessed by assigning the cells to one of 5 ocular dominance (OD) groups based on their response to monocular stimulation of the ipsilateral (ip) and contralateral (co) eye. An OD index was calculated as follows: OD $=($ co-ip $) / m$, with $m$ being the larger response. In OD group 1 $(\mathrm{OD} \geq 0.9)$ and $5(\mathrm{OD} \leq-0.9)$ neurons are exclusively driven by the contralateral (ipsilateral) eye. Group 2 neurons (OD 0.3-0.89) (group 4, OD -0.3 to -0.89 ) are dominated by the contralateral (ipsilateral) eye but in addition receive input from the ipsilateral (contralateral) eye. Group 3 neurons receive equal input from both eyes (OD 0.3 to -0.3 ).

Statistical analysis (Kruskal-Wallis one-way ANOVA by ranks, Dunn's multiple-comparison and $\chi^{2}$ test) was performed with SigmaStat 3.1 and GBstat 10.1, figures were prepared using SigmaPlot 8.0.

\section{Results}

In the present study we recorded 134 retinal slip cells in the NOTDTN of 4 infant macaques aged P9, P12, P14, and P60, and compared their response properties with our data from adult monkeys (Hoffmann and Distler, 1989; Hoffmann et al., 1991). In addition, we investigated the cortical input arising from areas V1 and MT to retinal slip cells by means of orthodromic electrical stimulation. Table 1 summarizes the data base of the study.

\section{Direction selectivity}

High direction selectivity for ipsiversive stimulus movement is characteristic for retinal slip neurons in the NOT-DTN of all adult mammals investigated so far, including the monkey. Here we show that in infant monkeys, NOT-DTN cells were already direction selective for ipsiversive movement (PD) shortly after birth (P9). Examples of direction selective responses in the 1-week-old (Fig. 1A), a 2-week-old (Fig. $1 B$ ), and the 2-month- 

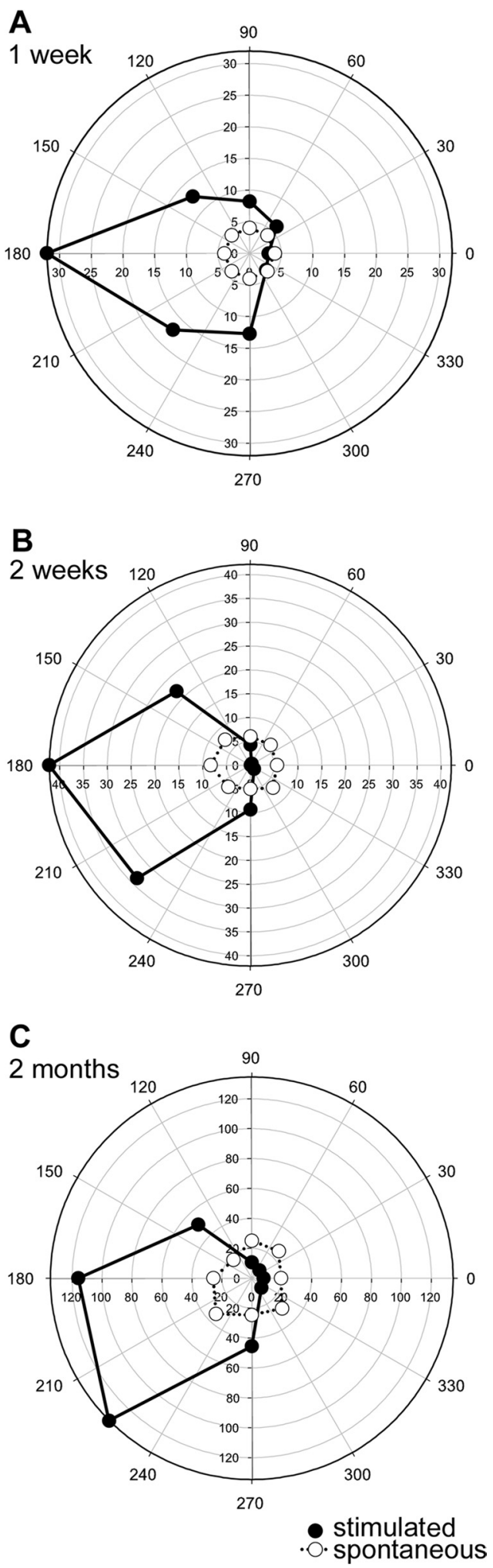

Figure 1. $\quad \boldsymbol{A}-\boldsymbol{C}$, Polar plots of exemplary NOT-DTN neurons recorded in a 1-week-old $(\boldsymbol{A})$, a 2-week-old (B), and a 2-month-old ( $\boldsymbol{C}$ infant macaque during optokinetic stimulation. Filled symbols and solid lines indicate the neuronal response during visual stimulation, open symbols and dotted lines indicate the neuron's spontaneous activity. In $A$, the spontaneous activity was recorded in a separate histogram, whereas in $\boldsymbol{B}$ and $\boldsymbol{C}$, the histogram was divided in spontaneous activity plus activity during movement in one plus activity during movement in the opposite direction. Thus, for the polar plots the spontaneous activity in the histogram of the appropriate stimulus direction was used. Numbers at the outer circle of the plots represent stimulus direction in degrees, numbers along the cardinal axes indicate neuronal activity in spikes/s.
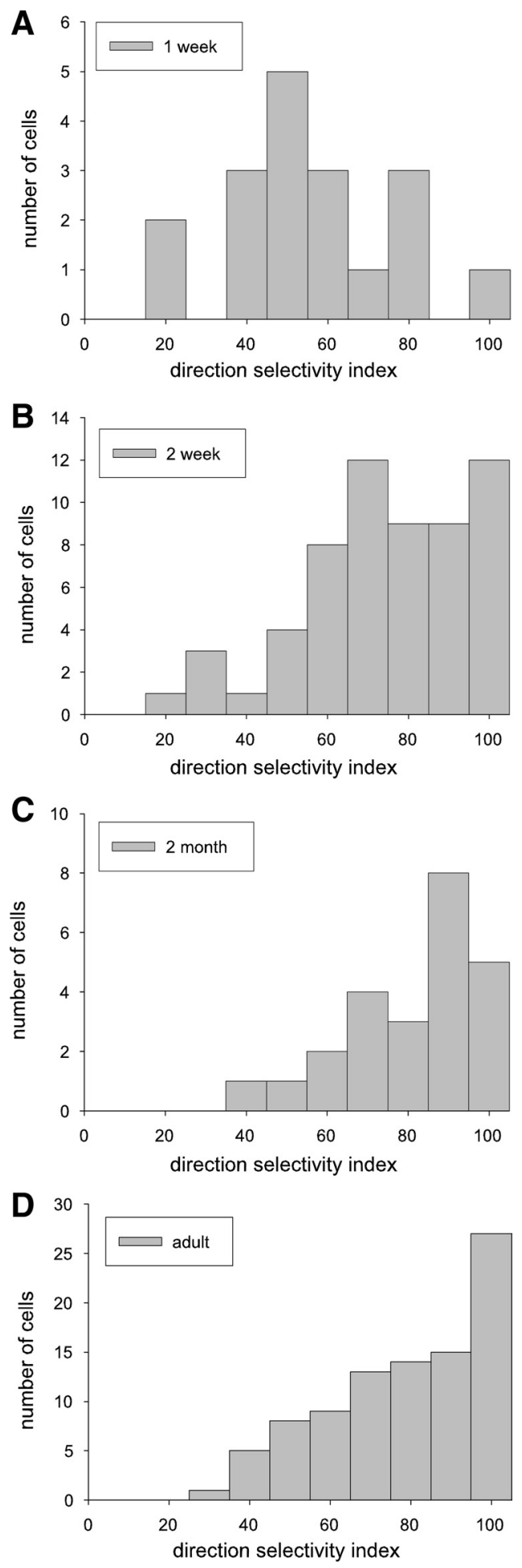

Figure 2. $\quad A-D$, Frequency histograms of direction selectivity indices of retinal slip neurons in 1-week-old ( $\boldsymbol{A}$ ), 2-week-old ( $\boldsymbol{B}$ ), 2-month-old ( $\boldsymbol{C}$, and adult macaques ( $\boldsymbol{D}$ ). Abscissa, Direction selectivity index; ordinate, number of cells. Note that in the 1-week-old animal most neurons display only moderate direction selectivity, whereas in older animals more neurons are highly selective.

old infant monkey (Fig. 1C) are given in the polar plots in Figure 1. Filled symbols and continuous lines indicate the stimulus driven activity, open symbols and dotted lines the spontaneous activity. Note that from 2 weeks onward activity is clearly depressed below spontaneous levels when the stimulus moves in 
contraversive directions (NPD). However, there were significantly less neurons with a high DSI $(\mathrm{DSI}=(\mathrm{PD}-\mathrm{NPD} / \mathrm{PD}) \times$ 100 ) than in the adult (Kruskal-Wallis, $p=0.018$ ). Figure 2 demonstrates the frequency distributions of DSIs in the 1-weekold (P9, median DSI = 61; Fig. 2 A), the 2-week-old (P12, median $\mathrm{DSI}=80, \mathrm{P} 14$, median DSI $=64.9, \mathrm{P} 12+\mathrm{P} 14$, median $=75.5$; Fig. $2 \mathrm{~B}$ ), the 2 -month-old monkeys (P60, median DSI $=70.4$; Fig. $2 C$ ), and in adults (median DSI $=77.4$; Fig. $2 D$ ). Data were taken from 4 adults: medians $=74.3,88.1,76.7$, and 69.2. A pairwise multiple-comparison procedure showed that only the data of the 1-week-old animal differ significantly from the adult animals (Dunn, $p<0.05$ ). The differences between the infant monkeys as well as between the adults were not significant. Thus, the direction selectivity index becomes adult-like as early as within the first 2 weeks of life although at a significantly lower activity level (see following paragraph). We also compared the DSIs during monocular stimulation of the contra- and the ipsilateral eye. Even though DSI was slightly higher during stimulation of the contralateral eye in 3 of the 4 infants and the adults this difference was never statistically significant (Mann-Whitney rank sum test $(p=0.3-0.07))$.

\section{Maximal stimulus driven activity}

Even though retinal slip cells were already direction selective in early infancy their maximal stimulus driven activity, i.e., the response vigor during stimulation in their preferred direction and preferred speed was significantly lower than in adult monkeys (Kruskal-Wallis one-way ANOVA, $p<0.0001$ ). In a case by case multiple-comparison procedure with Dunn's test the stimulus driven activities of the 4 infants were not different from each other (medians: P9: 35 spikes/s; P12: 39.3 spikes/s; P14: 37.1 spikes/s; P60: 31.1 spikes/s). The same was true for the 6 adults (medians 107 spikes/s; 62 spikes/s; 75.5 spikes/s; 68 spikes/s; 67 spikes/s; 73 spikes/s; see also Fig. 3). However, the values of 5 of the 6 adults were significantly higher than the values of any of the 4 infants $(p<0.05)$. For one adult the differences did not reach significance although its median was $>1.5$ times higher than any median of the infants. The frequency histograms in Figure 3 clearly show that in infant monkeys few cells (15\%) produced discharge rates $>70$ spikes/s (Fig. $3 A-C$ ), whereas in adults many cells $(>50 \%)$ discharged at $>70$ spikes/s (Fig. $3 D$ ). Another way to compare the responsiveness of NOT-DTN cells in different age groups is to consider the dynamic range between minimal and maximal stimulus driven activity. In the infant animals the medians of this range are similar with 15 spikes/s in the 9-d-old, 21 in the 2 -week-old and 24 in the 2-month-old animal. In 4 adults median values of 50-60 spikes/s were reached. The values of the 1- and 2-week-old animals are significantly lower than those in the adults (Dunn's multiple comparison, $p<0.05$ ). The difference between the 2-month-old animal and adults is not any more significant.

\section{Visual latency}

The visual latency is a measure of how brisk retinal slip cells react to the onset or change in the direction of stimulus movement. For this analysis only neurons with a high DSI index and a clearly detectable change in ongoing activity due to a change in stimulus direction were selected $(n=102)$. In infant monkeys visual latencies ranged from $90 \mathrm{~ms}$ to $>200 \mathrm{~ms}$ (Fig. 4A-C) (P9: median 183.5 ms, P12: median 187.5 ms, P14: median 153.5 ms, P12 + P14: median $166.5 \mathrm{~ms}, \mathrm{P} 60$ : median $175 \mathrm{~ms}$ ). These values were not different among the infants but significantly longer than visual latencies in adult NOT-DTN (Fig. 4D) (adult: median 59.9 ms, Kruskal-Wallis, $p<0.001$ ). Thus, the visual responses were
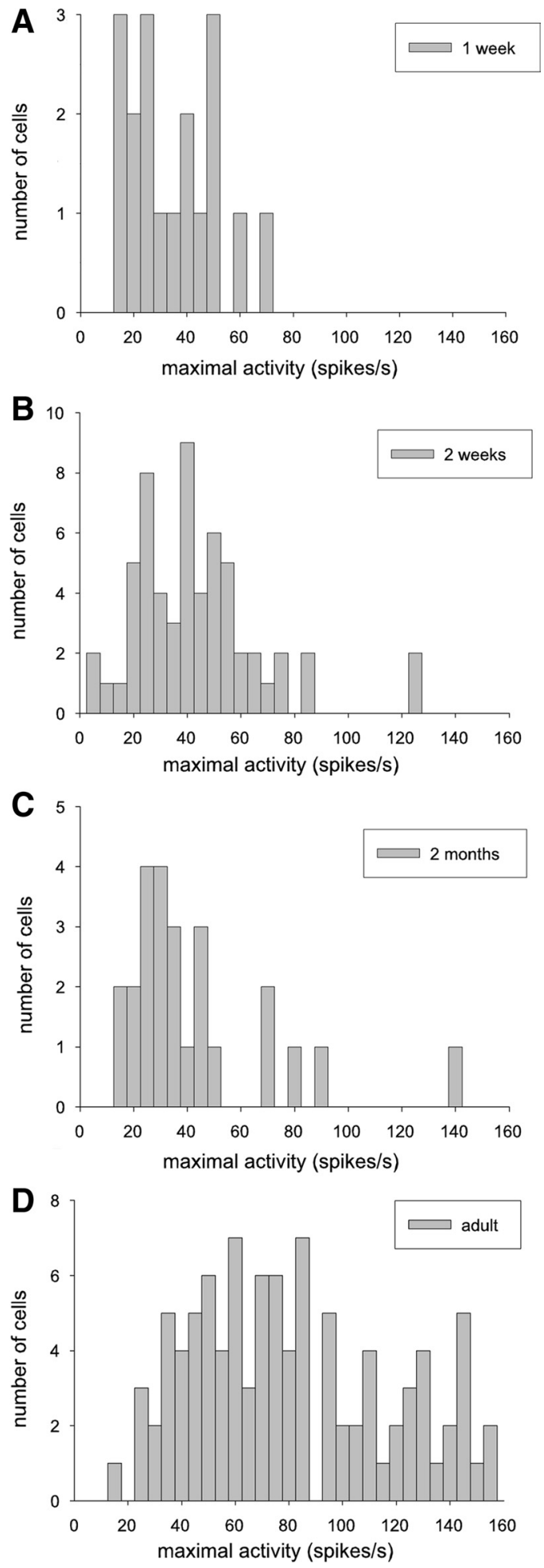

Figure 3. $A-D$, Frequency histograms of the maximal stimulus driven activity recorded from NOT-DTN neurons in 1-week-old $(\boldsymbol{A})$, 2-week-old $(\boldsymbol{B}), 2$-month-old $(\boldsymbol{C})$, and adult macaques (D). Abscissa, Maximal activity in spikes/s; ordinate, number of cells. Maximal activity is markedly lower in infant than in adult macaques.

rather sluggish in all infants tested and became brisker only during further maturation.

\section{Velocity tuning}

Retinal slip neurons reacted to visual stimuli moving at various velocities at all ages tested (Fig. 5). The range of effective stimulus 

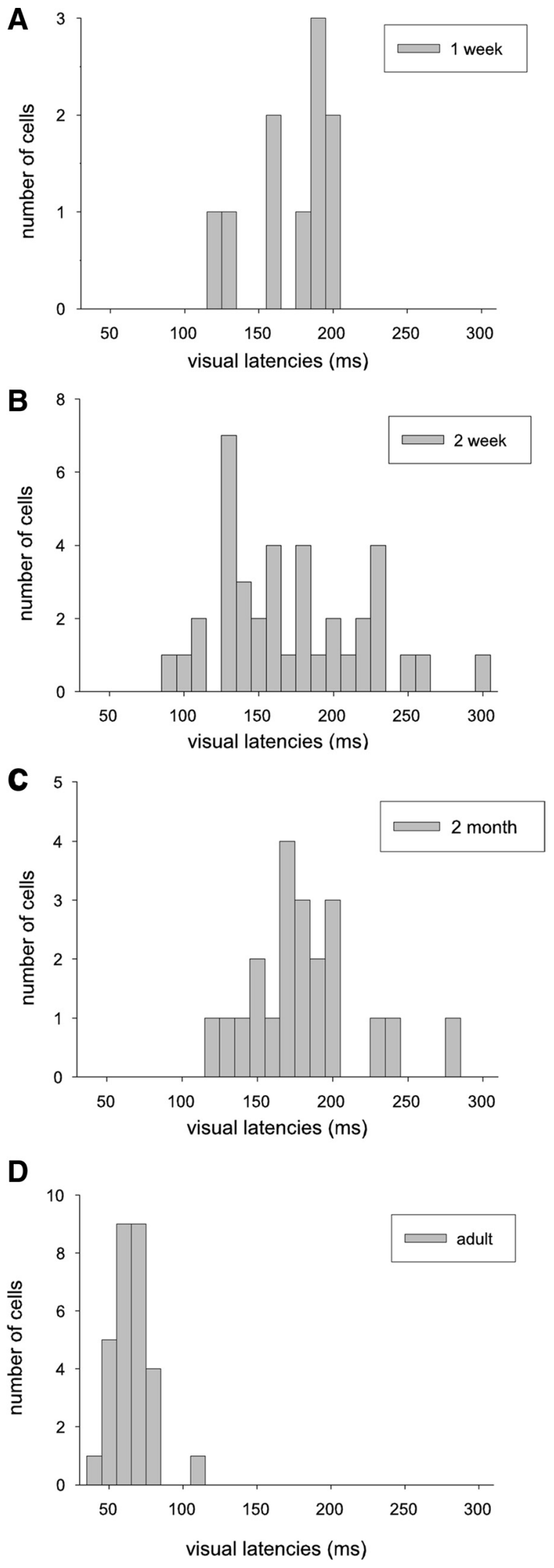

Figure 4. $A-D$, Frequency histograms of visual latencies measured in retinal slip cells of 1-week-old (A), 2-week-old (B), 2-month-old ( $\boldsymbol{C}$, and adult macaques (D). Abscissa, Visual latency in milliseconds; ordinate, number of cells. Visual latencies are significantly longer in infant than in adult monkeys.

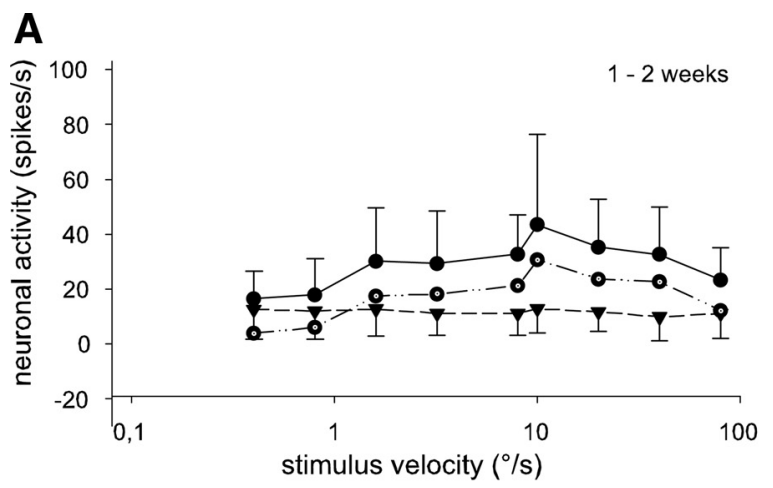

B
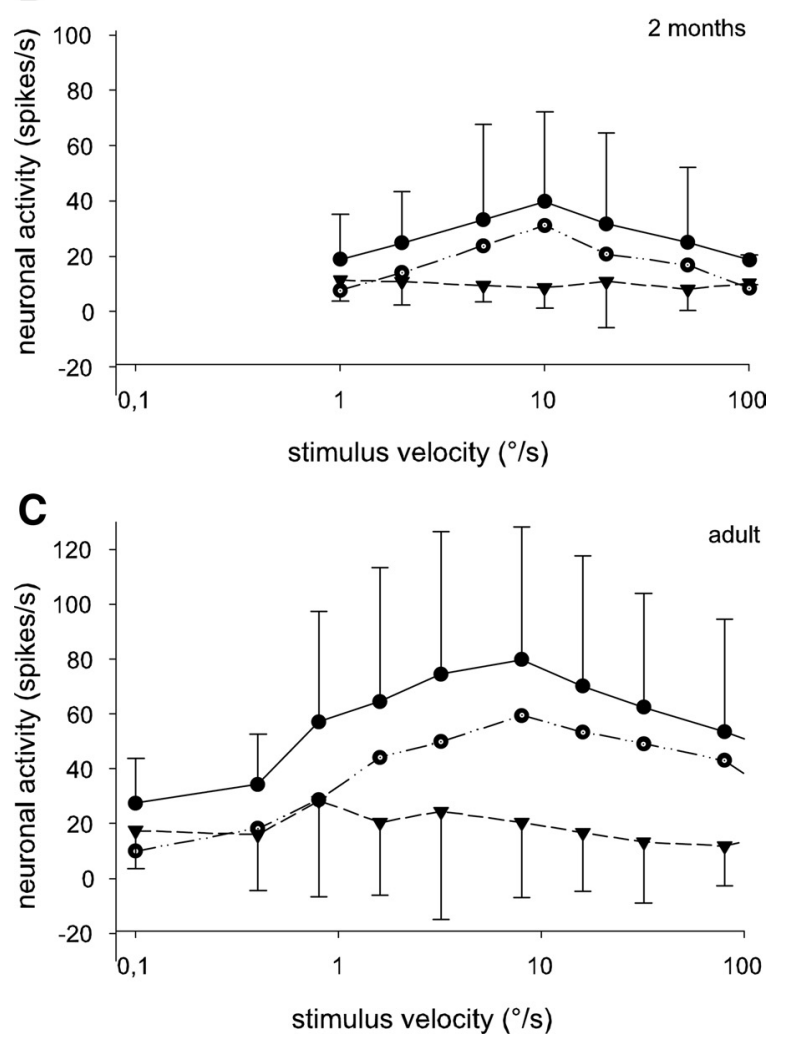

Figure 5. $\quad A-C$, Velocity tuning curves of retinal slip neurons of 1 - and 2-week-old monkeys $(\boldsymbol{A})$, of a 2-month-old animal (B), and of adult macaques (C). Abscissa, Stimulus velocity in degrees per second; ordinate, response strength in spikes/s. Filled dots with upward error bars and continuous lines indicate the mean activity and SD during stimulation in the preferred direction. Filled triangles, downward error bars, and broken lines indicate the mean activity and SD during stimulation in the non-preferred direction. Open circles and dashed lines indicate the neuronal modulation, i.e., the difference between activity during stimulation in preferred and non-preferred direction.

velocities leading to significant discharge differences in opposite directions varied between $0.1 \%$ and $>160 \%$ in adults (Fig. $5 \mathrm{C}$ ) but was more restricted to moderate velocities $(2-40 \%$ s) in infants (Fig. $5 A, B$ ). In fact, velocities below $1 \%$ did not lead to a significant elevation or depression of the ongoing activity. This finding was especially evident if one considered the neuronal modulation (Fig. 5, open circles), i.e., the difference between the neuronal activity during stimulation in the preferred (solid dots) and the non-preferred (solid triangles) direction. Overall the tuning curve based on neuronal modulation in infants was significantly lower in amplitude $(p<0.01$ in Dunn's multiple comparison) and different in shape from that of adult monkeys 
( $p<0.001$ in a $\chi^{2}$ test comparing the infant values to values expected from the adult values). In 1 - to 2 -week-old animals (Fig. $5 A$ ) and in the 2-month-old animal modulations $>20$ spikes/s were reached only at velocities $\sim 10 \%$ (Fig. $5 B$ ). For comparison, in adults velocities ranging from $1 \%$ s to $160 \%$ sielded neuronal modulations well above 20 spikes/s (Fig. 5C). In conclusion, shortly after birth and up to 2 months of age NOT-DTN neurons are most sensitive to stimulus velocities in the preferred range of adults $(10 \%)$. Only during further maturation, the range of effective velocities extents to very low and higher velocities and the neuronal modulation becomes stronger.

\section{Ocular dominance}

Binocularity in the NOT-DTN has long been considered the prerequisite for symmetrical mhOKR. Unexpectedly and different from kittens, the great majority of retinal slip cells received input from both eyes already at 1 week of age (Fig. 6). Nevertheless, in the 1- to 2-week-old animals $\sim 50-60 \%$ of the neurons were dominated by one eye (OD groups 1,2 and 4,5 ) with a strong bias for the contralateral eye (ratio contra/ipsi $=6: 1$ ) (Fig. $6 A, B)$. In the 2-month-old animal this ratio is only 2:1 (Fig. 6C). By contrast, in adults only $25 \%$ of the neurons in the NOT-DTN were not equally driven by both eyes (Fig. 6D). Thus, even though most NOT-DTN neurons receive input from both eyes already shortly after birth this binocular input becomes balanced between the contra- and ipsilateral eye only at an age of $>2$ months (Kruskal-Wallis one-way ANOVA, $p<0.05$, or $\chi^{2}$ test for equal OD distributions for infants and adults, $p<0.01$ ).

\section{Cortical input to the NOT-DTN}

Binocular convergence in the NOT-DTN can be achieved, first, by a bilateral retinal input or, second, by binocular cortical projections. Thus, we used orthodromic electrical stimulation to investigate the presence and efficiency of cortical projections arising from primary visual cortex $\mathrm{V} 1$ and from motion-sensitive area MT. In the P9 animal we were not able to elicit orthodromic potentials either in the SC or the NOT-DTN even though the receptive fields of the cortical stimulation sites were in register with the SC and NOT-DTN receptive fields.

In the 2-week-old animals electrical stimulation of $\mathrm{V} 1$ yielded orthodromic potentials in $41 \%(\mathrm{P} 12)$ and $61 \%(\mathrm{P} 14)$ of the NOT-DTN neurons tested. Success rates for pretectal units that were recorded close to (mostly below) the direction selective NOT-DTN neurons and for SC neurons were similar. The success rate for NOT-DTN neurons in the 2-month-old animal amounted to $64 \%$, and for pretectal units other than NOT-DTN to $83 \%$. In adults, $72 \%$ of the NOT-DTN neurons tested could be activated by electrical stimulation in V1. Although the trend shows clearly an increasing success rate with age the differences between the infants and adults were not statistically significant $\left(\chi^{2}, p>0.1\right)$. In the 2-month-old animal and in adults SC neurons were not tested on a regular basis.

In the P14 and the P60 animal we in addition electrically stimulated the cortical motion-sensitive area MT. In the 2-week-old infant $96 \%$ of the NOT-DTN neurons and $70 \%$ of other pretectal neurons tested could be activated from MT. In the 2-month-old monkey orthodromic potentials could be elicited in $88 \%$ of NOT-DTN and in $33 \%$ of other pretectal units. In adults, the success rate of MT stimulation was $80 \%$ for NOT-DTN neurons. Thus, the proportion of NOT-DTN neurons with input from MT seems to be adult-like already at 2 weeks of age, whereas the proportion of NOT-DTN neurons with input from V1 becomes adult-like a little later, certainly within 2 months after birth. An
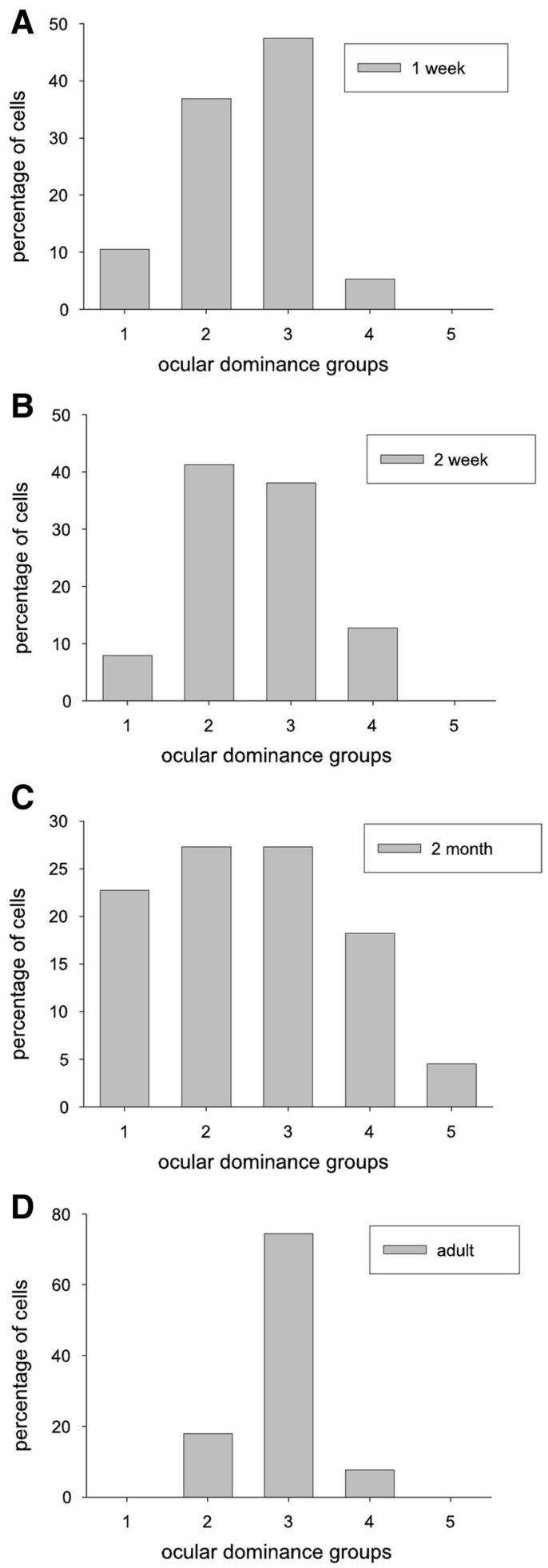

Figure 6. $\boldsymbol{A}-\boldsymbol{D}, 0$ cular dominance distributions of retinal slip cells of 1-week-old $(\boldsymbol{A})$, 2-week-old $(\boldsymbol{B})$, 2-month-old $(\boldsymbol{C})$, and adult macaques $(\boldsymbol{D})$. Abscissa, 0 cular dominance groups 1-5 (for definitions, see Materials and Methods); ordinate, percentage of cells. Even though there are many cells driven by both eyes already in very young animals, binocular input is balanced only in adults.

additional way to estimate the efficiency of electrical stimulation was to determine for the successfully stimulated subpopulation of NOT-DTN neurons how many action potentials were elicited per electrical pulse, e.g., 1 action potential for each pulse would amount to an efficiency of $100 \%$. It was evident that V1 stimula- 

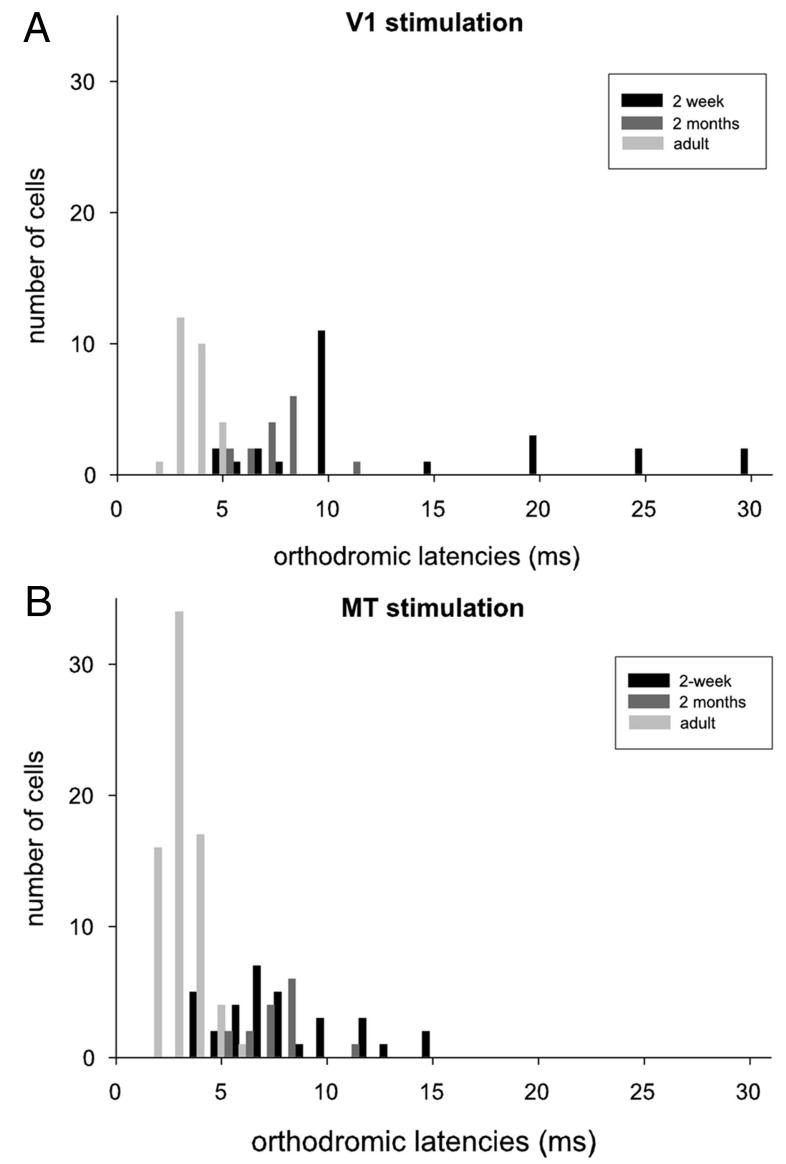

Figure 7. $\quad \boldsymbol{A}, \boldsymbol{B}$, Frequency histograms of latencies measured at NOT-DTN neurons after orthodromic electrical stimulation in area V1 $(\boldsymbol{A})$ and area MT $(\boldsymbol{B})$. Black bars represent data from 2-week-old macaques, dark gray bars, data from a 2-month-old infant, and light gray bars data from adult monkeys. Abscissa, Orthodromic latencies in milliseconds; ordinate, number of cells. Both V1 and MT-latencies shorten significantly during development.

tion elicited less spikes per pulse than MT stimulation. This was true for all age groups (2 weeks: V1 50\%, "low probability," MT 100\%, "high probability"; 2 months: V1 41\%, MT 71\%; adult: V1 $60 \%$, MT $100 \%$ ). Thus, the input to individual NOT-DTN neurons was always stronger from MT than from V1.

Orthodromic latencies of NOT-DTN neurons after V1 stimulation were significantly longer in infants than in adults (2 weeks: $13.3 \mathrm{~ms} \pm 7.6$, median $10 \mathrm{~ms} ; 2$ months: $7.1 \mathrm{~ms} \pm 1.3$, median $7 \mathrm{~ms}$; adult: $3.5 \mathrm{~ms} \pm 0.8$, median $3.5 \mathrm{~ms}$, Dunn's Method, $p<0.05$ ). Also after MT stimulation orthodromic latencies were significantly longer in 2-week-old infants but were comparable to adults in the 2-month-old animal (2 weeks: 8.0 $\mathrm{ms} \pm 3.0$, median $7.0 \mathrm{~ms} ; 2$ month: $3.45 \mathrm{~ms} \pm 1.3$, median $3 \mathrm{~ms}$; adult: $2.8 \mathrm{~ms} \pm 0.6$, median $3 \mathrm{~ms}$; Dunn's Method $p<0.05)$. The frequency distributions shown in Figure 7 demonstrate that in the 2-week-old animals a wide range of orthodromic latencies occurred after stimulation in V1 (Fig. 7A) and MT (Fig. 7B). This range of latencies shifted toward shorter latencies in the 2-month-old monkey and in adults.

\section{Relating electrophysiological and behavioral data}

To directly relate our electrophysiological experiments (this study) with longitudinal behavioral experiments in other individuals (Distler et al., 1999) we calculated a neuronal asymmetry index comparable to the OKR asymmetry factor used in the behavioral study. We have hypothesized that the output of the neu-

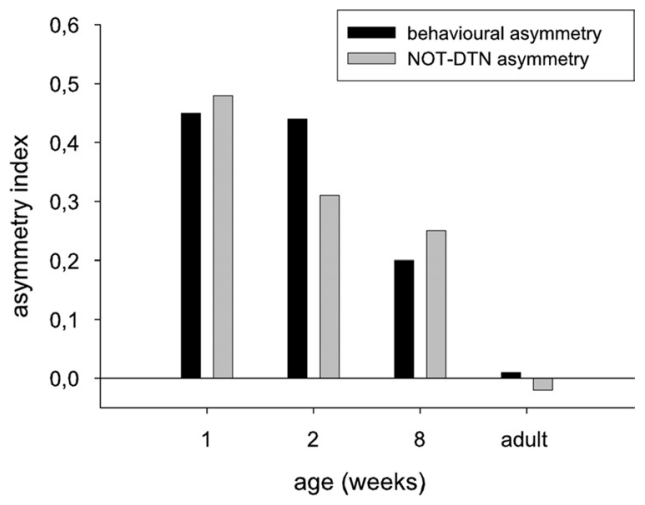

Figure 8. Relationship of OKR-asymmetry measured in behavioral experiments (black bars) and NOT-DTN neuronal activity asymmetry measured in electrophysiological experiments (gray bars). Abscissa, Age of the animals in weeks; ordinate, asymmetry index. There is a close similarity and developmental time course of the two parameters. For further explanations see text.

rons in the left and right NOT-DTN functions in a push-pull manner to drive OKR, i.e., the difference in activity between the left and the right NOT-DTN determines the direction and strength (gain) of the slow phase eye movements of the OKR during visual stimulation (Hoffmann, 1982). Since we never recorded from both NOT-DTNs simultaneously the following assumption was made. Recording from neurons in one NOT-DTN and stimulating each eye with leftward and rightward movements leads to the 4 NOT-DTN activity values necessary to calculate the neuronal equivalent of the gain of OKR: activation by the contralateral eye (A), suppression by the ipsilateral eye (B), activation by the ipsilateral eye $(C)$, suppression by the contralateral eye (D). If we assume the neurons in the two nuclei to behave in a mirror symmetric way, which is supported by all physiological data reported so far, we can use our data to estimate the effective activity differences between the 2 NOT-DTN populations driving the OKR. During monocular optokinetic stimulation the activity difference (A-B) between the activated contralateral NOT-DTN and the suppressed ipsilateral NOT-DTN would drive slow phase of OKR in temporonasal direction and the activity difference (C-D) between the activated ipsilateral NOT-DTN and the suppressed contralateral NOT-DTN would drive OKR in nasotemporal direction. A neuronal asymmetry index calculated as $[(\mathrm{A}-\mathrm{B})-(\mathrm{C}-\mathrm{D})] /(\mathrm{A}-\mathrm{B})$ should be equivalent to the asymmetry index of monocular OKR [(temporonasal gain) - (nasotemporal gain)]/(temporonasal gain) published by Distler et al. (1999).

These neuronal asymmetry indices were derived from neuronal activity at the best stimulus velocities and OKR asymmetry indices from the average over the velocity range tested because it was impossible to deduce the retinal slip velocity from the stimulus velocity minus the eye velocity with EOG recordings (see Distler et al., 1999, their Fig. 4). These indices are plotted against the age of the respective animals in Figure 8. There is a close correspondence between the activity asymmetry determined electrophysiologically and the mhOKR asymmetry determined behaviorally. This result seems difficult to reconcile with the ocular dominance distribution and velocity tuning at first, especially the difference between the ages of 2 weeks and 2 months. Note, however, that OD is calculated only from the activation of a neuron by the contra- and ipsilateral eye and velocity tuning from the modulation only by the contralateral eye, whereas the asymmetry index compares activation and suppression of neurons via the contra- and ipsilateral eye in the two NOT-DTNs. There is a clear increase in activation from the ipsilateral eye $(23 \%$ 
in the 2 -month-old versus $15 \%$ in the 2 -week-old; Fig. $6 C$ ) and a stronger suppression in the null direction (Fig. $5 B)(p<0.01$ in an $U$ test) in the 2-month-old animal which could explain the decreased asymmetry index compared with the 1- to 2-week-old animals.

\section{Discussion}

\section{Maturation of the optokinetic reflex and NOT-DTN}

In the present study we show that basic response characteristics of retinal slip cells in the NOT-DTN such as direction selectivity and binocularity are already present shortly after birth. Maximal stimulus driven neuronal activity, responses to various stimulus velocities, and latencies to onset of visual motion undergo significant changes early postnatally.

Cortical input to the NOT-DTN arising from V1 and MT is present at latest at 2 weeks of age, orthodromic latencies shorten, and frequency of elicited spikes per electrical pulse increases during further development indicating an increase in conduction velocity due to myelination and higher synaptic efficacy, respectively.

In a longitudinal study we showed that at $\mathrm{P} 3 \mathrm{mhOKR}$ is bidirectional in infant macaques. Symmetry of mhOKR, however, i.e., equal gain of $\mathrm{mhOKR}$ to temporonasal and to nasotemporal stimulus direction is achieved later. At low velocities $(10-20 \%$ s), symmetry is reached at 3-5 weeks of age; at higher velocities $(40-80 \%$ s), however, only after 5 months of age (Distler et al., 1999). In the present study the differences in the neuronal population responses of the two NOT-DTNs between monocular stimulation in nasotemporal and temporonasal direction were as asymmetrical as the OKR gains measured behaviorally at corresponding ages.

A similar study in kittens demonstrated a striking temporal coincidence between onset of OKR symmetry, onset of binocular responses in the NOT-DTN, and onset of functional connections of cortical projections to the NOT-DTN (Distler and Hoffmann, 1993). Lesion studies in primates demonstrate the relevance of striate and extrastriate visual cortical areas for unperturbed slow eye movements and symmetric mhOKN (e.g., Ter Braak and Van Vliet, 1963; Lynch and McLaren, 1983; Zee et al., 1987; Dürsteler and Wurtz, 1988). As we failed to reveal a cortical input to the NOT-DTN at P9, binocularity in the NOT-DTN up to this age should indeed originate from the direct projections of retinal ganglion cells from both eyes (Ballas et al., 1981; Kourouyan and Horton, 1997; Telkes et al., 2000). However, already at P12 and P14, we could convincingly demonstrate a direct cortical projection to the NOT-DTN arising from V1 and even more strongly from MT which, however, did not increase binocular balance at once, i.e., a large proportion of neurons was still dominated by the contralateral eye. Balanced binocularity in the infant NOTDTN was not even seen at 2 months of age and therefore probably develops in visual cortex during a long period of visual experience. NOT-DTN neurons were direction selective already at P9. We assume that this subcortical direction selectivity originates from direction selective ganglion cells in the retina present at birth like in other mammals (Hoffmann, 1983; Hoffmann et al., 1995; Elstrott et al., 2008). The increase in the direction selectivity index at 2 weeks of age, however, could be due to maturation of local circuits, e.g., GABAergic inhibition, and/or cortical input.

Similar to our results in the NOT-DTN, Movshon et al. (2003) demonstrated that direction selectivity of neurons in cortical area MT was present 1 week after birth. Interestingly, maximal stimulus driven activity was lower in the NOT-DTN of infant monkeys than in adults (our study) but was significantly higher than in MT most prominently in the 1- to 4-week-old animals (Movshon et al., 2003). Visual latencies of MT neurons were substantially longer in the 1 - and 4-week-old animals than in adults and very similar to our values in NOT-DTN at similar age (Movshon et al., 2003).

The lower firing rate in infant NOT-DTN neurons could be caused by various factors. Immature ion conductances preclude action potentials to be created at higher frequencies (Rothe et al., 1999). In visual cortex, the transient neuronal responses in V1 and V2 are adult-like shortly after birth, whereas the sustained component is not (Zhang et al., 2008) probably due to synapse depression and immature membrane properties (Shaw et al., 1991; Markram and Tsodyks, 1996; Abbott et al., 1997; Carandini and Ferster, 1997, 2000). As formation of the fovea occurs prenatally in macaques (Kirby and Steineke, 1992; Provis et al., 1998) it is unlikely that retinal maturation plays a crucial role in the changes of response properties observed in the present study (but see Jacobs and Blakemore, 1988).

We interpret the observed changes in response properties of NOT-DTN cells in infant macaques as a neuronal phenomenon. However, the optics of the eye are quite immature early after birth in macaques (Hung et al., 1995; Qiao-Grider et al., 2007). We tried to optimize the optics of our animals with contact lenses chosen with a Rodenstock refractometer. We did not measure the spatial frequency sensitivity in the infant NOT-DTN neurons. Behavioral data, however, suggest that spatial frequency sensitivity develops over the first year of life and therefore very likely was immature in our infants (P9-P60) (Boothe et al., 1988). We ameliorated this effect by adjusting the coarseness of the stimulation patterns.

Together, important properties of neurons in the NOT-DTN were qualitatively almost adult-like shortly after birth in infant monkeys. Cortical lesion and inactivation studies in adult primates and human infants indicate that subcortical mechanisms enable infants to perform a clear nasotemporal component during mhOKR already at P3 in monkeys (Distler et al., 1999) and human infants before 10 months of age (Morrone et al., 1999). The further maturation of NOT-DTN response properties seen as increase in peak activity, shortening of visual latencies and strengthening of the input of the ipsilateral eye leading to an improvement of the mhOKR during nasotemporal stimulation can probably be attributed to the maturation of cortical areas and their projections to the NOT-DTN. The long time course might correspond to the prolonged process of myelination and local circuit formation in primate cortex as revealed histologically and with magnetic resonance imaging (Rodman, 1994; Condé et al., 1996; Gogtay et al., 2004; Kourtzi et al., 2006; Malkova et al., 2006; Deoni et al., 2011). Interestingly, area MT like primary sensory areas shows adult-like immunohistochemistry within the first postnatal month (Bourne and Rosa, 2006). In the motor system conduction velocity becomes adult-like only at 11 months of age (Armand et al., 1994).

Altogether, there is a remarkable similarity in the development of response characteristics in the NOT-DTN and MT. Already at 2 weeks of age a cortical projection originating especially from MT could reliably be demonstrated underpinning MT's early functional contribution to OKR. Electrical stimulation of MT always yielded stronger orthodromic responses than stimulation of V1 thus corresponding to our anatomical results in adult monkeys that identify MT as the main source of cortical input to the NOT-DTN (Distler and Hoffmann, 2001; Distler et al., 2002). 


\section{Maturation of OKR compared with other visual functions}

In general, behavioral development can be linked to the maturation of certain cortical areas. In monkeys, stereopsis starts to develop at $\sim 8$ weeks of age (O'Dell and Boothe, 1997). Spatial discrimination (grating acuity) and positional discrimination (vernier acuity) develop over the first $8-10$ postnatal months but at different rates (Kiorpes and Movshon, 1989). In V1 and V2 the transient but not the sustained component of neuronal firing is adult-like soon after birth (Zhang et al., 2008). The temporal response properties and contrast sensitivity develop at $4-8$ weeks after birth (Zheng et al., 2007). Ocular dominance distribution and the number of disparity-sensitive neurons is adult-like shortly after birth, but their optimal spatial frequency is significantly lower than in adults thus limiting binocular depth perception (Chino et al., 1997; Maruko et al., 2008). Direction selectivity is poor, with a nasotemporal bias at 1 week but rapidly improves during the first 4 weeks. Thus, these properties do not match well or are even opposite to the properties of NOT-DTN neurons (Chino et al., 1997; Hatta et al., 1998).

Object recognition memory is present at 4 months of age (Bachevalier and Mishkin, 1984) matching the adult-like glucose consumption in the cortical pathway for object recognition at that age (Bachevalier et al., 1991). Further maturation lasts for several months after birth (Webster et al., 1991; Rodman, 1994). Glucose consumption in the cortical pathway for motion analysis was adult-like at 3 months of age. However, this developmental time course was neither reflected in the development of OKR symmetry (Distler et al., 1996, 1999) nor of basic response properties of MT neurons (Movshon et al., 2003). Detection of coherent motion occurs $\sim 2$ weeks of age, perception of moving plaid patterns starts only at $\sim 3$ months of life. Both improve significantly over the first year of life (Kiorpes and Movshon, 2004; Hall-Haro and Kiorpes, 2008).

Thus, maturation of various visual functions seems to mirror maturation of mainly cortical circuits as well as myelination of the brain. Investigating OKR in early infancy can serve as a viable method with high predictive power for normal or abnormal development of subcortical and cortical properties in the pathways analyzing visual motion in primate and human infants.

\section{References}

Abbott LF, Varela JA, Sen K, Nelson SB (1997) Synaptic depression and cortical gain control. Science 275:220-224.

Armand J, Edgley SA, Lemon RN, Olivier E (1994) Protracted postnatal development of corticospinal projections from the primary motor cortex to hand motoneurones in the macaque monkey. Exp Brain Res 101:178-182.

Asanuma H, Sakata H (1967) Functional organisation of a cortical efferent system examined with focal depth stimulation in cats. J Neurophysiol 30:35-45.

Atkinson J (1979) Development of optokinetic nystagmus in the human infant and the monkey infant: an analogue to development in kittens. In: Developmental neurobiology of vision (Freeman RD, ed), pp 277-287. New York: Plenum.

Bachevalier J, Mishkin M (1984) An early and a late developing system for learning and retention in infant monkeys. Behav Neurosci 98:770-778.

Bachevalier J, Hagger C, Mishkin M (1991) Functional maturation of the occipitotemporal pathway in infant rhesus monkeys. In: Alfred Benzon symposium 31, Brain work and mental activity (Lassen NA, Ingvar DH, Raichle ME, Friberg L, eds), pp 231-240. Copenhagen: Munksgaard.

Ballas I, Hoffmann KP, Wagner HJ (1981) Retinal projection to the nucleus of the optic tract in the cat as revealed by retrograde transport of horseradish peroxidase. Neurosci Lett 26:197-202.

Boothe RG, Kiorpes L, Williams RA, Teller DY (1988) Operant measurements of contrast sensitivity in infant macaque monkeys during normal development. Vision Res 28:387-396.
Bourne JA, Rosa MG (2006) Hierarchical development of the primate visual cortex, as revealed by neurofilament immunoreactivity: early maturation of the middle temporal area (MT). Cereb Cortex 16:405-414.

Braddick O, Atkinson J, Wattam-Bell J (2003) Normal and anomalous development of visual motion processing: motion coherence and "dorsal stream vulnerability". Neuropsychologia 41:1769-1784.

Büttner-Ennever JA, Cohen B, Horn AK, Reisine H (1996) Efferent pathways of the nucleus of the optic tract in monkey and their role in eye movements. J Comp Neurol 373:90-107.

Carandini M, Ferster D (1997) A tonic hyperpolarization underlying contrast adaptation in cat visual cortex. Science 276:949-952.

Carandini M, Ferster D (2000) Membrane potential and firing rate in cat primary visual cortex. J Neurosci 20:470-484.

Cechetto DF, Diab T, Gibson CJ, Gelb AW (2001) The effects of propofol in the area postrema of rats. Anesth Analg 92:934-942.

Chen K, Godfrey DA (2000) Sodium pentobarbital abolishes bursting spontaneous activity of dorsal cochlear nucleus in rat brain slices. Hearing Res 149:216-222.

Chino YM, Smith EL 3rd, Hatta S, Cheng H (1997) Postnatal development of binocular disparity sensitivity in neurons of the primate visual cortex. J Neurosci 17:296-307.

Condé F, Lund JS, Lewis DA (1996) The hierarchical development of monkey visual cortical regions as revealed by the maturation of parvalbuminimmunoreactive neurons. Dev Brain Res 96:261-276.

Deoni SC, Mercure E, Blasi A, Gasston D, Thomson A, Johnson M, Williams SC, Murphy DG (2011) Mapping infant brain myelination with magnetic resonance imaging. J Neurosci 31:784-791.

Distler C, Hoffmann KP (1993) Visual receptive field properties in kitten pretectal nucleus of the optic tract and dorsal terminal nucleus of the accessory optic tract. J Neurophysiol 70:814-827.

Distler C, Hoffmann KP (2001) Cortical input to the nucleus of the optic tract and dorsal terminal nucleus (NOT-DTN) in macaques: a retrograde tracing study. Cereb Cortex 11:572-580.

Distler C, Bachevalier J, Kennedy C, Mishkin M, Ungerleider LG (1996) Functional development of the corticocortical pathway for motion analysis in the macaque monkey: a ${ }^{14} \mathrm{C}$-2-deoxyglucose study. Cereb Cortex 6:184-195

Distler C, Vital-Durand F, Korte R, Korbmacher H, Hoffmann KP (1999) Development of the optokinetic system in macaque monkeys. Vision Res 39:3909-3919.

Distler C, Mustari MJ, Hoffmann KP (2002) Cortical projections to the nucleus of the optic tract and dorsal terminal nucleus and to the dorsolateral pontine nucleus in macaques: a dual retrograde tracing study. J Comp Neurol 444:144-158.

Distler C, Korbmacher H, Hoffmann KP (2009) Retinal projections to the accessory optic system in pigmented and albino ferrets (Mustela putorius furo). Exp Brain Res 199:333-343.

Dürsteler MR, Wurtz RH (1988) Pursuit and optokinetic deficits following chemical lesions of cortical areas MT and MST. J Neurophysiol 60:940-965.

Elstrott J, Anishchenko A, Greschner M, Sher A, Litke AM, Chichilnisky EJ, Feller MB (2008) Direction selectivity in the retina is established independent of visual experience and cholinergic retinal waves. Neuron 58:499-506.

Gogtay N, Giedd JN, Lusk L, Hayashi KM, Greenstein D, Vaituzis AC, Nugent TF 3rd, Herman DH, Clasen LS, Toga AW, Rapoport JL, Thompson PM (2004) Dynamic mapping of human cortical development during childhood through early adulthood. Proc Natl Acad Sci U S A 101:8174-8179.

Grewing M (2004) Auswirkungen des Opioids Fentanyl auf die neuronale Aktivität visueller Strukturen der Katze und den Serumcortisolspiegel unter Allgemeinanästhesie. Doctoral thesis, Tierärztliche Hochschule Hannover and Ruhr-Universität Bochum.

Hall-Haro C, Kiorpes L (2008) Normal development of pattern motion sensitivity in macaque monkeys. Vis Neurosci 25:675-684.

Hatta S, Kumagami T, Qian J, Thornton M, Smith EL 3rd, Chino YM (1998) Nasotemporal directional bias of V1 neurons in young infant monkeys. Invest Ophthalmol Vis Sci 39:2259-2267.

Hoffmann KP (1982) Cortical versus subcortical contributions to the optokinetic reflex in the cat. In: Functional basis of ocular motility disorders. (Lennerstrand G, Zee DS, Keller EL et al., eds), pp 303-310, Oxford: Pergamon. 
Hoffmann KP (1983) Effects of early monocular deprivation on visual input to cat nucleus of the optic tract. Exp Brain Res 51:236-246.

Hoffmann KP, Distler C (1989) Quantitative analysis of visual receptive fields of neurons in the nucleus of the optic tract and dorsal terminal nucleus of the accessory optic tract in macaque monkey. J Neurophysiol 62:416-428.

Hoffmann KP, Distler C, Erickson R (1991) Functional projections from striate cortex and superior temporal sulcus to the nucleus of the optic tract (NOT) and dorsal terminal nucleus of the accessory optic tract (DTN) of macaque monkeys. J Comp Neurol 313:707-724.

Hoffmann KP, Distler C, Mark RF, Marotte LR, Henry GH, Ibbotson MR (1995) Neural and behavioral effects of early eye rotation on the optokinetic system in the wallaby, Macropus eugenii. J Neurophysiol 73:727-735.

Hoffmann KP, Bremmer F, Distler C (2009) Visual response properties of neurons in cortical areas MT and MST projecting to the dorsolateral pontine nucleus or the nucleus of the optic tract in macaque monkeys. Eur J Neurosci 29:411-423.

Hung LF, Crawford ML, Smith EL (1995) Spectacle lenses alter eye growth and the refractive status of young monkeys. Nat Med 1:761-765.

Hyvärinen J, Laakso M, Roine R, Leinonen L (1979) Comparison of effects of pentobarbital and ethanol on the neuronal activity in the posterior parietal association cortex. Acta Physiol Scand 107:219-225.

Jacobs DS, Blakemore C (1988) Factors limiting the postnatal development of visual acuity in the monkey. Vision Res 28:947-958.

Kaitin KI (1985) Effects of thalidomide and pentobarbital on neuronal actovoty in the preoptic area during sleep and wakefulness in the cat. Psychopharmacology 85:47-50.

Kalberlah C, Distler C, Hoffmann KP (2009) Sensitivity to relative disparity in early visual cortex in pigmented and albino ferrets. Exp Brain Res 192:379-389.

Kiorpes L, Movshon JA (1989) Differential development of two visual functions in primates. Proc Natl Acad Sci U S A 86:8998-9001.

Kiorpes L, Movshon JA (2004) Development of sensitivity to visual motion in macaque monkeys. Vis Neurosci 21:851-859.

Kirby MA, Steineke TC (1992) Morphogenesis of retinal ganglion cells during formation of the fovea in the rhesus macaque. Vis Neurosci 9:603-616

Kourouyan HD, Horton JC (1997) Transneuronal retinal input to the primate Edinger-Westphal nucleus. J Comp Neurol 381:68-80.

Kourtzi Z, Augath M, Logothetis NK, Movshon JA, Kiorpes L (2006) Development of visually evoked cortical activity in infant macaque monkeys studied longitudinally with fMRI. Magn Reson Imaging 24:359-366.

Logothetis NK, Guggenberger H, Peled S, Pauls J (1999) Functional imaging of the monkey brain. Nat Neurosci 2:555-562.

Lynch JC, McLaren JW (1983) Optokinetic nystagmus deficits following parieto-occipital cortex lesions in monkeys. Exp Brain Res 49:125-130.

Malach R, Strong N, Van Sluyters RC (1981) Analysis of monocular optokinetic nystagmus in normal and visually deprived kittens. Brain Res 210:367-372.

Malkova L, Heuer E, Saunders RC (2006) Longitudinal magnetic resonance imaging study of rhesus monkey brain development. Eur J Neurosci 24:3204-3212.

Markram H, Tsodyks M (1996) Redistribution of synaptic efficacy between neocortical pyramidal neurons. Nature 382:807-810.

Maruko I, Zhang B, Tao X, Tong J, Smith EL 3rd, Chino YM (2008) Postnatal development of disparity sensitivity in visual area 2 (V2) of macaque monkeys. J Neurophysiol 100:2486-2495.

Mason AJ, Braddick OJ, Wattam-Bell J (2003) Motion coherence thresholds in infants-different tasks identify at least two distinct motion systems. Vision Res 43:1149-1157.

Morrone MC, Atkinson J, Cioni G, Braddick OJ, Fiorentini A (1999) Developmental changes in optokinetic mechanisms in the absence of unilateral cortical control. Neuroreport 10:2723-2729.

Movshon JA, Rust NC, Kohn A, Kiorpes L, Hawken MJ (2003) Receptive field properties of MT neurons in infant macaques. Soc Neurosci Abstr 29:126.8.
Mustari MJ, Fuchs AF, Kaneko CR, Robinson FR (1994) Anatomical connections of the primate pretectal nucleus of the optic tract. J Comp Neurol 349:111-128.

Naegele JR, Held R (1982) The postnatal development of monocular optokinetic nystagmus in infants. Vision Res 22:341-346.

Nowak LG, Bullier J (1996) Spread of stimulating current in the cortical grey matter of rat visual cortex studied on a new in vitro slice preparation. J Neurosci Methods 67:237-248.

O'Dell C, Boothe RG (1997) The development of stereoacuity in infant rhesus monkeys. Vision Res 37:2675-2684.

Olds ME, Ito M (1973) Effects of chlorpromazine, chlordiazpoxide and pentobarbital on neuronal excitability in the medial forebrain bundle during self-stimulating behaviour. Neuropharmacology 12:1117-1133.

Provis JM, Diaz CM, Dreher B (1998) Ontogeny of the primate fovea: a central issue in retinal development. Progr Neurobiol 54:549-581.

Qiao-Grider Y, Hung LF, Kee CS, Ramamirtham R, Smith EL 3rd (2007) Normal ocular development in young rhesus monkeys (Macaca mulatta). Vision Res 47:1424-1444.

Riecanský I, Thiele A, Distler C, Hoffmann KP (2005) Chromatic sensitivity of neurones in area MT of the anaesthetised macaque monkey compared to human motion perception. Exp Brain Res 167:504-525.

Rodman HR (1994) Development of inferior temporal cortex in the monkey. Cereb Cortex 5:484-498.

Ronner SF, Foote WE, Pollen DA (1981) Intracortical microstimulation of neurons in the visual cortex of the cat. Electroencephalogr Clin Neurophysiol 52:375-377.

Rothe T, Jüttner R, Bähring R, Grantyn R (1999) Ion conductances related to development of repetitive firing in mouse retinal ganglion neurons in situ. J Neurobiol 38:191-206.

Sewards TV, Sewards MA (2002) Innate visual object recognition in vertebrates: some proposed pathways and mechanisms. Comp Biochem Physiol A Mol Integr Physiol 132:861-891.

Shaw C, Cameron L, March D, Cynader M, Zielinski B, Hendrickson A (1991) Pre- and postnatal development of GABA receptors in macaca monkey visual cortex. J Neurosci 11:3943-3959.

Simpson JI, Giolli RA, Blanks RHI (1988) The pretectal nuclear complex and the accessory optic system. In: Neuroanatomy of the oculomotor system (Buettner-Ennever JA, ed), pp 335-364. Amsterdam: Elsevier.

Tehovnik EJ, Tolias AS, Sultan F, Slocum WM, Logothetis NK (2006) Direct and indirect activation of cortical neurons by electrical microstimulation. J Neurophysiol 96:512-521.

Telkes I, Distler C, Hoffmann KP (2000) Retinal ganglion cells projecting to the nucleus of the optic tract and the dorsal terminal nucleus of the accessory optic system in macaque monkeys. Eur J Neurosci 12:2367-2375.

Ter Braak JWG, Van Vliet A (1963) Subcortical optokinetic nystagmus in the monkey. Psychiatr Neurol Neurochir 66:277-283.

Van Hof-Van Duin J (1978) Direction preference of optokinetic responses in monocularly tested normal kittens and light deprived cats. Arch Ital Biol 116:471-477.

Wang N, Zhang Y, Wang JY, Gao G, Luo F (2010) Effects of pentobarbital anesthesia on nociceptive processing in the medial and lateral pain pathways in rats. Neurosci Bull 26:188-196.

Webster MJ, Ungerleider LG, Bachevalier J (1991) Connections of inferior temporal areas TE and TEO with medial temporal-lobe structures in infant and adult monkeys. J Neurosci 11:1095-1116.

Zee DS, Tusa RJ, Herdman SJ, Butler PH, Gücer G (1987) Effects of occipital lobectomy upon eye movements in primate. J Neurophysiol 58:883-907.

Zhang B, Smith EL 3rd, Chino YM (2008) Postnatal development of onset transient responses in macaque V1 and V2 neurons. J Neurophysiol 100:1476-1487.

Zheng J, Zhang B, Bi H, Maruko I, Watanabe I, Nakatsuka C, Smith EL 3rd, Chino YM (2007) Development of temporal response properties and contrast sensitivity in V1 and V2 neurons in macaque monkeys. J Neurophysiol 97:3905-3916. 